\title{
The role of predictability in the stress response of a cichlid fish
}

\author{
Leonor Galhardo $^{\mathrm{a}, *}$, Joana Vital ${ }^{\mathrm{a}}$, Rui F. Oliveira ${ }^{\mathrm{a}, \mathrm{b}}$ \\ a Unidade de Investigação em Eco-Etologia, Instituto Superior de Psicologia Aplicada, Rua Jardim do Tabaco, 34, 1149-041 Lisboa, Portugal \\ b Champalimaud Neuroscience Programme, Instituto Gulbenkian de Ciência, Rua da Quinta Grande, 6, 2780-156 Oeiras, Portugal
}

\section{A R T I C L E I N F O}

\section{Article history:}

Received 28 January 2010

Received in revised form 24 November 2010

Accepted 30 November 2010

Available online $\mathrm{xxxx}$

\section{Keywords:}

Stress

Appraisal

Predictability

Anticipatory behaviour

Tilapia

\begin{abstract}
A B S T R A C T
In recent years there has been an increasing interest in the cognitive abilities of fish with implications for animal welfare and management of rearing operations. Although it is known that psychological factors can modulate the stress response in mammals, this aspect has seldom been investigated within stress in fish. In this study we investigate whether the perception (appraisal) that fish make of significant environmental events modifies their behavioural and physiological response. For this purpose we have used a predictable vs. unpredictable paradigm for positive (feeding) and negative (confinement) events using the cichlid fish Oreochromis mossambicus as a model species.

Results show that there is a differential effect of predictability for the feeding and confinement events. In the confinement experiment, predictability involved more attention to the visual cue and lower cortisol. The feeding event triggered higher levels of anticipatory behaviour and a tendency for higher cortisol in the predictable group. Therefore, predictable negative events reduce the cortisol response. Predictable positive events may elicit an anticipatory response, and when there is a significant delay between the visual cue and the actual occurrence of the event, it may also contain elements that can be interpreted as a stress response. These findings demonstrate that fish can appraise relevant aspects of the environment, with welfare implications for housing, husbandry and experimental procedures.
\end{abstract}

(C) 2010 Elsevier Inc. All rights reserved.

\section{Introduction}

The relevance of psychological factors in the modulation of the stress response became clear in the second half of last century [1]. The same sensory input may produce a completely different output, depending on the way the stressor is appraised by different individuals or by the same individual in different contexts. The appraisal process involves two stages in which cognitive and emotional areas of the brain are involved. The first stage (primary appraisal) involves the perception of the event and evaluation of its properties on the basis of previous memory and learned facts. The second stage (secondary appraisal) involves the assessment of the available coping mechanisms $[2,3]$. In humans, the appraisal mechanism involves the frontal areas of the cortex, where the cognitive evaluation takes place, and areas of the limbic system (hippocampus and amygdala), where the emotional valence is defined [4]. While the appraisal concept has already been applied to the study of emotions in mammals [5], in fish the whole concept of psychological stress has been rarely addressed.

The physiological and behavioural stress response in fish is well known and it is very similar to that of other vertebrates [6]. However, very little is known on the effect of psychological components on

\footnotetext{
* Corresponding author. Tel.: +351 218811700; fax: +351 218860954. E-mail address: leonor_galhardo@ispa.pt (L. Galhardo).
}

stress and there is even a current debate on whether fish possess certain mental abilities, in particular whether fish possess the emotional component of pain $[7,8]$. Despite this, recent studies of pain and fear suggest that teleosts may feel the unpleasant sensory and emotional experience in a similar way as other vertebrates $[9,10]$. Fish receive and process sensory inputs in the forebrain, have homologous areas to the tetrapods' limbic structures and similar neurotransmitter systems [11-13]. Furthermore, the recent finding of corticosteroid receptors in the forebrain of carp [14], strongly suggest that the regulation of the stress response starts above the level of hypothalamus, which is in line with recent studies showing how learning and memory of fish can be disrupted by high cortisol levels during stressful contexts [e.g. 15]. A number of studies also show evidence of far more complex fish behavioural and cognitive capacities than previously described $[12,16]$. Therefore, despite missing knowledge on exact mechanisms, fish are likely to have the necessary central mechanisms for the psychological assessment of environmental stimuli related to stress (appraisal) [for a review, see 17].

Predictability of events (i.e. the perceived occurrence of a stimulus [3]), is one of the most discussed psychological modulators of the stress response $[18,19]$, and therefore we use it here to test for the occurrence of appraisal in fish. One of the earliest studies on the effects of predictability was undertaken by Weiss [20] in rats with electric shocks. He found that the same intensity and duration shocks, when delivered in a predictable way, produced less physiological 
responses and less gastric ulcers. Since then, several studies on the effects of predictability of aversive and attractive events have been developed. Basset and Buchanan-Smith [21] have reviewed these studies and their effects on the well being of animals. Predictability of aversive events is more associated to lower stress responses than unpredictability $[22,23]$ despite some inconsistent results attributed to different study lengths and to the inappropriate comparison of different stress measurements [21]. In fact, unpredictability, even for biologically non-relevant events, is enough to stimulate the amygdala, a limbic structure responsible for contextual emotional learning [24]. Concerning positive events, which are usually food-related, the relationship of predictability with stress signals is less clear. A number of studies, especially based on behavioural parameters, indicate that predictable feeding regimes are less stressful for the animals [25-28]. However, other studies point out in a different direction: predictable schedules induce high levels of anticipatory behaviours, characterised by increased general activity, with eventual stereotypic behaviour [29-31]. Sánchez and colleagues [32] have studied the effects of a random and scheduled feeding regime on sea bream levels of cortisol and concluded that the latter regime stimulated anticipatory behaviour and higher cortisol levels in this species. Loss of predictability (predictable followed by unpredictable regimes) is clearly reported as a source of stressful behavioural and physiological responses $[21,25,27,30]$. Furthermore, the relieving effect of predictability depends on a number of aspects related to the stressor's properties (nature, intensity and frequency) as well as on the reliability of the signalling system $[19,21]$.

In this study we investigate how males of a cichlid fish, the Mozambique tilapia (Oreochromis mossambicus), cope with the presentation of signalled predictable and unpredictable events that differ in their valence: 1) negative event - confinement stress (confinement experiment); 2) positive event - feeding episode (feeding experiment). The working hypothesis is that predictability will produce differential behavioural and physiological stress responses according to the valence of the stimulus.

\section{Methods}

\subsection{Animals and housing}

72 0. mossambicus males were used in this study (confinement experiment, $\mathrm{n}=29$; feeding experiment, $\mathrm{n}=24$; isolation control, $\mathrm{n}=19$; average weight, $99.5 \pm 3.8 \mathrm{~g}$ ). Females were not used in order to decrease potential variability in the sample. The fish belong to a stock held at ISPA and were maintained in glass aquaria $(120 \times 40 \times 50 \mathrm{~cm}, 240 \mathrm{l})$ with a fine gravel substrate, in stable social groups of 3-5 males and 5-6 females. The temperature was held at $26{ }^{\circ} \mathrm{C} \pm 2{ }^{\circ} \mathrm{C}$, with a $12 \mathrm{~L}: 12 \mathrm{D}$ photoperiod. Tanks were equipped with a double filtering system (sand and external biofilter, Eheim) and constant aeration. Water quality was analysed weekly for nitrites (0.2-0.5 ppm), ammonia (<0.5 ppm) (Pallintest kit $\left.{ }^{8}\right)$ and pH (6.06.2). Fish were fed daily ad libitum with commercial cichlid sticks (ASTRA).

\subsection{Experimental aquaria and set up}

Under experimental conditions, the animals were housed individually in testing aquaria of approximately $401(50 \times 25 \times 30 \mathrm{~cm})$. The remaining conditions were the same as described for the stock tanks. Aquaria were covered at the sides with opaque partitions in order to avoid visual contact between animals. The confinement aquaria $(21 \times 19 \times 35 \mathrm{~cm})$ were placed next to the experimental ones, also in visual isolation and filled with 21 of water (enough to cover the body height, with the dorsal fin closed) and no substrate.

The experimental set up was the same for the two experiments, with the exception of the nature of the stimuli/stressor used: a confinement paradigm, as a negative event (confinement experiment) and feeding, as a positive event (feeding experiment). A schematic representation of the experimental set up is presented in Fig. 1. Both experiments involved a paired design, with predictable and unpredictable balanced treatments. Each experiment lasted for 19 days, during which the animals were maintained isolated in the experimental aquaria to control for variation due to different social ranks $[33,34]$. A blood sampling for control plasma cortisol took place at day 4, training occurred at days 8-9 (predictable or unpredictable treatment) and days 17-18 (unpredictable or predictable treatment), immediately followed by the test trials at day 10 and 19, respectively. Since the control group in our experiments was in social isolation and since social isolation is known to affect baseline levels of cortisol [35-38], we assessed the effects of social isolation on cortisol levels by sampling a group of males in three different contexts: in stable groups in stock tanks, and after 4-days and after 10-days of social isolation.

\subsection{Visual cue, valence events, training and trial procedures}

Predictability was signalled in both experiments by means of a visual cue consisting of a yellow and black stripped card $(20 \times 20 \mathrm{~cm})$. The card was placed on the outside of the aquarium lateral wall, remained in view of the fish for $5 \mathrm{~min}$ before the occurrence of the signalled event: confinement (confinement experiment) or food (feeding experiment). The unpredictable treatment involved the presentation of the same sign dissociated from the subsequent event, that is, at least 30 min before or after the session in a random way.

The negative valence event (confinement) consisted quickly capturing (preventing chasing) the animal from the experimental aquarium with a hand net and placing it in the confinement aquarium, described above, for $30 \mathrm{~min}$. This paradigm, with variable methodologies, has been generally adopted as a stress test in fish [e.g. 39]. Behavioural sampling was undertaken during the first $10 \mathrm{~min}$ and blood sampling for plasma cortisol measurement at the end of the confinement period.

The positive valence event (feeding) consisted of the delivery of two pellets of the usually used commercial food for cichlids per session (four training sessions per day covered the individual daily portion). These pellets fluctuate for some time before swelling and sinking. Usually, fish take them from the surface. The pellets were delivered in the front part of the aquarium using the opposite corner at which the signal for predictable treatments was given.

Each experiment involved eight training sessions, developed during 2 days, at 10.00, 12.00, 14.00 and $16.00 \mathrm{~h}$. A study developed in our laboratory has shown that males of this species can be conditioned within six to eight training sessions [40]. A schematic representation of the predictable and unpredictable training is presented in Fig. 1. The trials took place the day after the 2-day training sessions at $10.00 \mathrm{~h}$. In the confinement experiment, confinement took place as usual immediately after the presentation of the visual signal. During the training sessions of the feeding experiment, fish of predictable treatment became conditioned to relate signalling with food presentation. For this reason, and in order to avoid anaesthesia-related complications during digestion, in the trial fish were anaesthetised immediately after the signal presentation, without being given food.

\subsection{Behavioural and blood sampling and cortisol assay}

Behaviour during signalling was recorded by means of 5 min scan sampling, with a total of 10 sampling points per individual [41]. In the confinement experiment, only 12 out of the total 29 involved animals were observed during the presentation of the visual cue while the whole set of fish was sampled in the feeding experiment $(n=24)$. Behaviour during confinement was also sampled through scan sampling, during the first $10 \mathrm{~min}$ of the test, with a total of 60 


\begin{tabular}{|c|c|c|c|c|c|c|}
\hline Days & $1-7$ & $8-9$ & 10 & $11-16$ & $17-18$ & 19 \\
\hline Procedure & $\begin{array}{c}\text { Isolation } \\
\text { for } \\
\text { baseline } \\
\text { cortisol }\end{array}$ & $\begin{array}{c}\text { Training } \\
\text { for } \\
\text { predictable } \\
\text { treatment }\end{array}$ & Trial & Isolation & $\begin{array}{c}\text { Training } \\
\text { for } \\
\text { unpredictable } \\
\text { treatment }\end{array}$ & Trial \\
\hline
\end{tabular}

\section{Training sessions:}

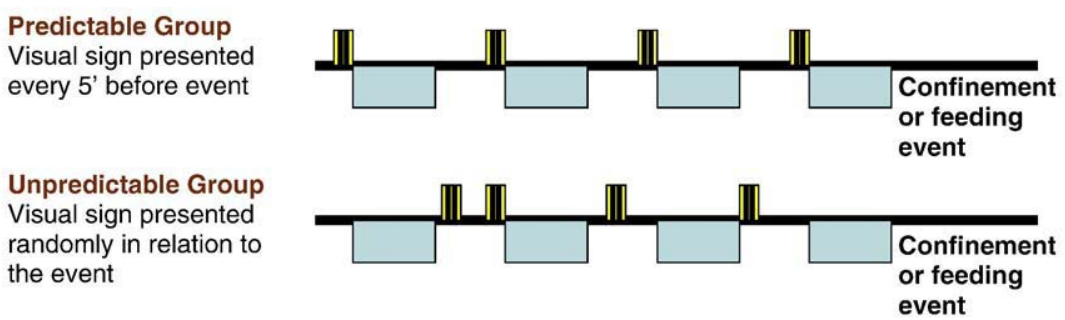

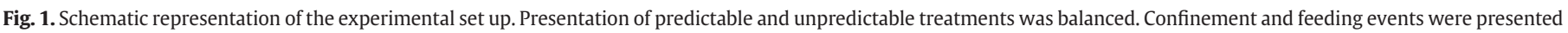
in different experiments, involving 29 and 24 fish respectively.

sampling points. The behavioural activities and position of fish in the tank were noted as described in Table 1.

At the end of the confinement experiment 1, fish were lightly anaesthetised in the confinement aquarium without additional disturbance (Stage two anaesthesia following [42]) by adding a solution of MS-222 (tricaine methane sulphonate, Sigma; 200 ppm) to the water. Samples of $100-200 \mu \mathrm{l}$ of blood were taken from the caudal vein ( $1 \mathrm{ml}$ syringes; $25 \mathrm{G} / 16 \mathrm{~mm}$ needles). The fish were then

Table 1

Brief description of the behaviour patterns and use of specific areas of the aquaria adopted for sampling.

\begin{tabular}{|c|c|c|}
\hline Context & Behavioural pattern & Description \\
\hline \multirow[t]{2}{*}{ General } & Swimming (SWI) & $\begin{array}{l}\text { Fish moves in the water column } \\
\text { or in the bottom at any speed or } \\
\text { intensity of body movements } \\
\text { without major water disturbance. }\end{array}$ \\
\hline & Inactive (INA) & $\begin{array}{l}\text { Fish remains immobile, but with } \\
\text { some fin movements, in touch } \\
\text { with the substrate or/and } \\
\text { hovering. }\end{array}$ \\
\hline \multirow[t]{3}{*}{$\begin{array}{l}\text { Position in the aquarium } \\
\text { during signalling }\end{array}$} & Close (CLO) & $\begin{array}{l}\text { Fish remains inactive or } \\
\text { swimming with the head within } \\
2 \mathrm{~cm} \text { in front of the sign. }\end{array}$ \\
\hline & Front (FRO) & $\begin{array}{l}\text { Fish remains inactive or } \\
\text { swimming in the front half part } \\
\text { of the aquarium, with the } \\
\text { exception of the area in front } \\
\text { of the sign. }\end{array}$ \\
\hline & Back (BAC) & $\begin{array}{l}\text { Fish remains inactive or } \\
\text { swimming in the back half } \\
\text { part of the aquarium. }\end{array}$ \\
\hline \multirow[t]{2}{*}{ During signalling* } & Sign attention (SIG) & $\begin{array}{l}\text { Fish inspects (faces the signal } \\
\text { while swimming or inactive } \\
\text { within approximately } 12 \mathrm{~cm} \\
\text { in front of the signal) or } \\
\text { interacts (touches, bites) } \\
\text { with the sign. }\end{array}$ \\
\hline & Anticipation (ANT) & $\begin{array}{l}\text { Fish swims constant and rapidly } \\
\text { with vertical movements along } \\
\text { the front glass of the aquarium } \\
\text { interspersing this with } \\
\text { frequent surfacing in the area } \\
\text { where the food is usually placed. }\end{array}$ \\
\hline \multirow[t]{2}{*}{ During confinement } & Escaping (ESC) & $\begin{array}{l}\text { Fish swims strongly provoking } \\
\text { water disturbance and moving } \\
\text { the body in a way that resembles } \\
\text { escape attempts. }\end{array}$ \\
\hline & Freezing (FRE) & $\begin{array}{l}\text { Fish remains inactive and without } \\
\text { fins movement, in the substrate. }\end{array}$ \\
\hline
\end{tabular}

* These behaviours were only sampled in the feeding experiment. placed in aerated water, recovering from the anaesthesia within $30 \mathrm{~s}$ to one minute. Blood sampling was performed within a maximum of $4 \mathrm{~min}$ from the induction of anaesthesia, which is within the latency for cortisol release into the systemic circulation in response to handling stress in this species [43].

Free cortisol fraction was extracted from the plasma by adding diethyl ether to the sample, as the steroid solvent. The samples were then centrifuged $\left(5 \mathrm{~min}, 1000 \mathrm{rpm}, 4^{\circ} \mathrm{C}\right.$ ) and frozen $\left(10 \mathrm{~min},-80^{\circ} \mathrm{C}\right)$ to separate the ether fraction. The steroids were isolated by evaporating the ether. This process was repeated twice. Levels of free cortisol fraction were then determined by radioimmunoassay, using the commercial antibody 'Anti-rabbit, Cortisol-3' [ref: 20-CR50, Interchim (Fitzgerald), Montluçon, France, cross-reactivity: cortisol $100 \%$, Prednisolone 36\%, 11-Desoxycortisol 5.7\%, Corticosterone 3.3\%, Cortisone $<0.7 \%$ ] and the radioactive marker $[1,2,6,7-3 \mathrm{H}]$ Cortisol [ref: TRK407-250mCi, Amersham Biosciences, Piscataway, NJ/USA]. Intraand inter-assay variability were respectively as follows: experiment 1 , $3.8 \%$ and 5.9\%; experiment 2 and 'cortisol control', 5.8\% and 6.5\%.

\subsection{Data analysis}

All analyses were conducted using the statistical package Statistica V.8.0® (StatSoft Inc, USA, 1984-2008). For analysis of cortisol among treatments (baseline/predictable/unpredictable) and for the 'cortisol control', a one-way repeated measures ANOVA was used followed by planned comparisons of least squares means. Comparisons between cortisol levels in stock (social group) and in predictable and unpredictable treatments were made by a t-test for independent samples. Behavioural comparisons of predictable vs. unpredictable treatments were carried out using Wilcoxon Matched Pairs Test. A significance value of $P<0.05$ was used in all statistical tests.

\subsection{Ethical note}

The experiments described were conducted in accordance to national legal standards on protection of animals used for experimental purposes and are part of a project approved by the national authorities (Ref. 30489, 29/11/2007).

\section{Results}

\subsection{Confinement experiment}

During stimulus signalling, the animals spent more time close to the visual sign in the predictable treatment than in the unpredictable 

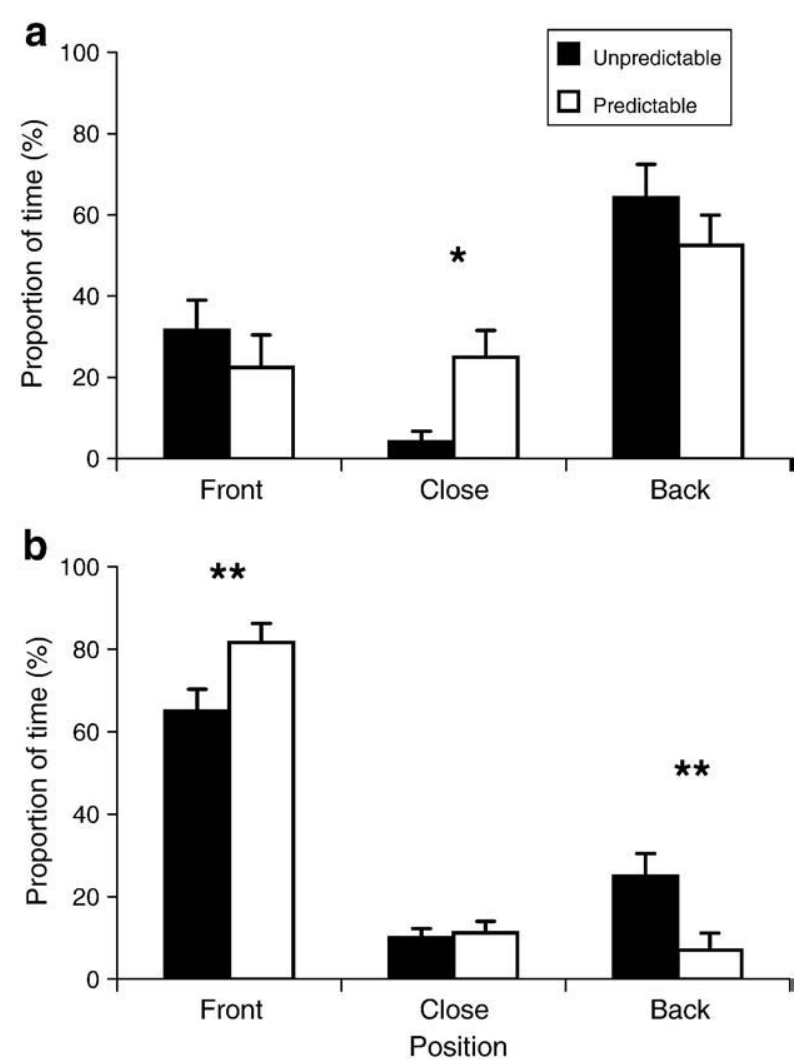

Fig. 2. Proportion of time (\%) spent in different areas of the aquarium (front, back and close to the visual cue) during signalling of (a) confinement and (b) feeding. ${ }^{*} \mathrm{P}<0.05$ $* * \mathrm{P}=0.001$.

one (Wilcoxon matched pairs test, $Z=2.4, P=0.02[n=12]$; Fig. $2 a$ ). There were no differences in the use of the front or back parts of the aquarium between treatments (Wilcoxon matched pairs test, front and back: $\mathrm{Z}=0.8$, ns $[\mathrm{n}=12]$; Fig. $2 \mathrm{a})$.

During confinement, no differences between treatments were found in frequency of swimming (Wilcoxon matched pairs test, $Z=0.9$, ns $[\mathrm{n}=29]$ ) and inactivity (Wilcoxon matched pairs test, $\mathrm{Z}=1.4$, ns $[n=29])$. However, freezing behaviour tended to be more frequent in the unpredictable treatment (Wilcoxon matched pairs test, $\mathrm{Z}=1.7$, $P=0.09[n=29])$. Escaping was very rare in both treatments.

Cortisol levels of the predictable treatment were significantly lower than those of both the control group (measured in social isolation) and of the unpredictable treatment (one-way repeated measures ANOVA, $\mathrm{F}_{(2,54)}=6.9, \mathrm{P}<0.01$, planned comparisons of $\mathrm{LS}$ means $\mathrm{P}=0.005$, Table 2, Fig. 4).

Table 2

Mean \pm standard error of cortisol values ( $\mathrm{ng} / \mathrm{ml}$ ) in (a) confinement (b) feeding (c) cortisol control in stock and after 4 and 10 days of isolation. Letters a and b express differences between treatments (one-way repeated measures ANOVA, planned comparisons of least square means, $\mathrm{P}<0.01 ;{ }^{*} \mathrm{P}=0.09$ for difference between predictable and unpredictable treatment; ${ }^{* *} \mathrm{P}=0.08$ for difference between 4 and 10 days of isolation).

\begin{tabular}{llll}
\hline & Control & Predictable & Unpredictable \\
\hline $\begin{array}{c}\text { (a) Confinement } \\
\mathrm{n}=28\end{array}$ & $43.0 \pm 5.1^{\mathrm{a}}$ & $21.8 \pm 3.2^{\mathrm{b}}$ & $42.3 \pm 5.4^{\mathrm{a}}$ \\
$\begin{array}{c}\text { (b) Feeding } \\
\mathrm{n}=24\end{array}$ & $45.9 \pm 3.8^{\mathrm{a}}$ & $32.9 \pm 3.0^{\mathrm{b}^{*}}$ & $25.6 \pm 3.5^{\mathrm{b}^{*}}$ \\
& Stock & 4-days isolation & 10-days isolation \\
\hline $\begin{array}{c}\text { (c) Control } \\
\mathrm{n}=19\end{array}$ & $13.3 \pm 2.7^{\mathrm{a}}$ & $35.0 \pm 4.9^{\mathrm{b}^{* *}}$ & $55.1 \pm 9.6^{\mathrm{b}^{* *}}$ \\
& & &
\end{tabular}

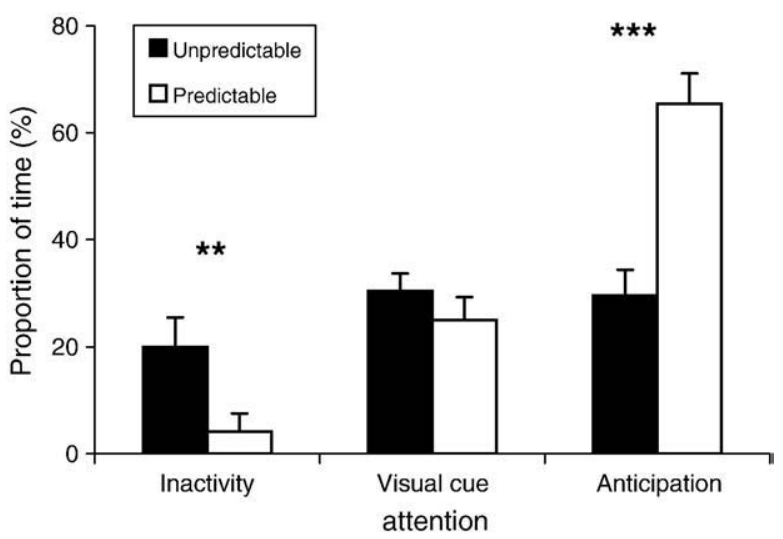

Fig. 3. Proportion of time (\%) spent in different behavioural patterns during the feeding event signalling. ${ }^{* *} \mathrm{P}<0.01{ }^{* * *} \mathrm{P}<0.001$.

\subsection{Feeding experiment}

During stimulus signalling, the animals spent the same amount of time close to the visual sign in the predictable and in the unpredictable treatment (Wilcoxon matched pairs test, $\mathrm{Z}=0.5$, ns $[\mathrm{n}=24]$; Fig. 2b). Also no difference between treatments was found for attention towards visual cue (Wilcoxon matched pairs test, $\mathrm{Z}=1.1$, ns [n=24]; Table 1, Fig. 3). However, there were differences in the use of space: animals spent more time in the front areas of the aquarium in the predictable treatment (Wilcoxon matched pairs test, $Z=3.3, P=0.001[n=24]$; Fig. $2 b$ ) and in the back in the unpredictable one (Wilcoxon matched pairs test, $\mathrm{Z}=3.2, \mathrm{P}=0.002$ $[\mathrm{n}=24]$; Fig. 2b). Levels of activity were also measured, with a higher inactivity being shown during the unpredictable treatment (Wilcoxon matched pairs test, $\mathrm{Z}=2.6, \mathrm{P}=0.009[\mathrm{n}=24]$; Fig. 3). During signalling, levels of anticipatory behaviour were significantly higher in animals subjected to the predictable treatment (Wilcoxon matched pairs test, $\mathrm{Z}=3.9, \mathrm{P}<0.001$ [ $\mathrm{n}=24]$; Table 1 , Fig. 3 ).

In relation to control levels (measured in isolation), cortisol levels tended to be lower during the unpredictable treatment than during the predictable treatment (one-way repeated measures ANOVA, $\mathrm{F}_{(2,46)}=12.3, \mathrm{P}<0.001$, planned comparisons of LS means $\mathrm{P}=0.09$; Table 2 and Fig. 4).

\subsection{Effects of social isolation}

Males exhibited the lowest levels of cortisol when they were housed in stable social groups (stock), and significantly increased when they were placed in social isolation (one-way repeated measures ANOVA, $\mathrm{F}_{(2,36)}=11.3, \mathrm{P}<0.001$, planned comparisons of LS means $\mathrm{P}<0.001)$. Although, in the confinement experiment cortisol levels did not increase in response to the confinement stressor, they

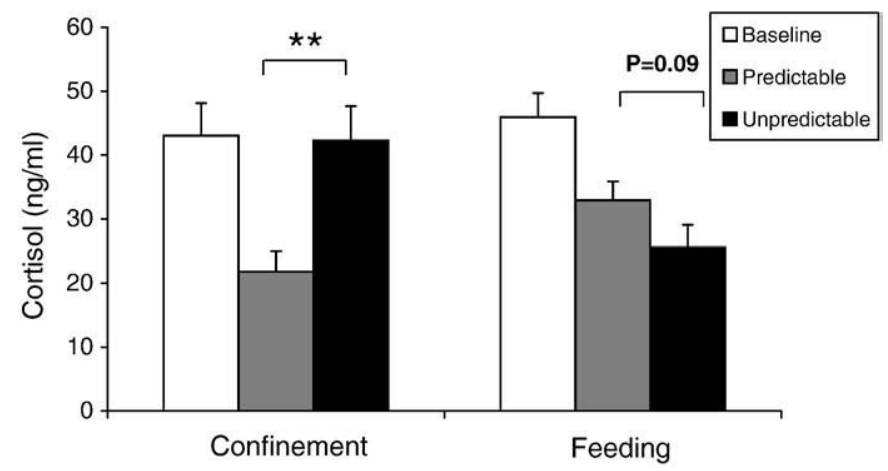

Fig. 4. Cortisol levels in the baseline, predictable and unpredictable treatments after (a) confinement and (b) feeding events. ${ }^{* *} \mathrm{P}<0.01$. 
are significantly higher in the unpredictable treatment (t-test, $\mathrm{t}(45)=$ $-4,19, \mathrm{P}=0,0001$ ) and marginally non-significant in the predictable treatment ( $\mathrm{t}$-test, $\mathrm{t}(45)=-1,89, \mathrm{P}=0,06)$ when compared to the baseline levels in a social group.

\section{Discussion}

The current study suggests that the fish response to stressors and positive events is modified by their appraisal of the situation (i.e. predictable vs. unpredictable). There is a differential effect of predictability depending on the valence of the event in relation to the negative (confinement) and positive (feeding) events. In the confinement experiment, the predictable group paid more attention to the visual sign, expressed less freezing behaviour and a diminished cortisol response in relation to the baseline in social isolation. On the other hand, the signalling of food presentation triggered higher levels of anticipatory behaviour and activity in the predictable group. Despite the decreased cortisol levels in relation to the baseline in social isolation in the predictable group, there was a more marked cortisol decrease in the unpredictable group in response to food.

\subsection{Predictability of a negative valence event (confinement experiment)}

During confinement, the males subjected to the predictable treatment tended to show less freezing behaviour and showed lower cortisol levels. Freezing behaviour is a well known inhibitory response to stress and it has been previously described for fish under stressful contexts [e.g. 44,45]. Together, the behaviour under confinement and the cortisol response, strongly suggest that the males subjected to the predictable treatment were less stressed than males in the unpredictable treatment. This is in line with the cognitive activation theory of stress, whereby predictability decreases the degree of discrepancy between internal expectancies (set values) and the reality (actual value), with the concomitant decrease in levels of arousal and stress response [3]. These results are also consistent with many published studies on the effect of predictability of aversive events in other species [22,23]. The animals seemed to pay more attention to the visual cue in the predictable treatment, as judged by the time they spent close to it, suggesting that the cue was being investigated and, thus, its meaning processed accordingly. The 'safety signal hypothesis', discussed by Basset and Buchanan-Smith [21], suggests that predictability is less stressful because it signals the safety periods in the absence of cue. Additionally, predictability may provide a perception of control, as it allows self-preparation of the incoming event, even if only internally and not through behaviour [22].

\subsection{Predictability of a positive valence event (feeding experiment)}

When the stimulus was food, there was no difference in attentiveness to the visual cue (as measured by time close by or exploration) between the predictable and unpredictable treatments. However, a very conspicuous difference was noted in increased activity and anticipatory behaviour by the predictable group. The occurrence of increased activity and anticipatory behaviour in predictable feeding schedules is in accordance with many other studies where 'Food Anticipatory Activity' has been reported [21,29]. These studies rarely show physiological data related to the expression of anticipatory behaviour. However, in a study of feeding predictability in sea bream, Sánchez et al. [32] also observed an increased cortisol response associated to anticipatory behaviour. While some authors highlight the role of anticipatory behaviour as an expression of positive emotions in animals [e.g. 46], its subjective meaning has been less discussed [but see also 47]. In our view, the meaning of anticipatory behaviour in relation to well being is inextricably linked to the delay between the triggering signal and the onset of the expected event. If it is short enough, the expression of anticipatory behaviour may mean arousal related to positive emotions, also expressed by means of less aggression and more exploratory behaviour [e.g. 48]. This is the case in a number of studies where predictable schedules for positive events is reported as positive and where time period between the signal and the event was only of some seconds $[49,50]$. However, in studies of temporal predictability (fixed times) or when the time span between the signal and the expected event is longer (from minutes to hours), this may induce expectation, frustration and indeed some loss of control (and, thus, unpredictability). In this case, animals may engage in high levels of anticipatory behaviour, even stereotypies, with related aggression and other stress-related behaviours $[27,29]$. To be also noted that some reported beneficial predictable feeding schedules may be due to experimental designs where the unpredictable treatment represented in fact a loss of predictability [e.g. 51]. In the present study, the increased anticipatory behaviour and cortisol suggest that $5 \mathrm{~min}$ of food signalling may be an enough delay to potentially develop negative subjective effects in Mozambique tilapia. But additional data would be needed to definitely associate the observed anticipatory behaviour with frustration. Therefore, levels of arousal observed in the predictable feeding may be subjectively linked to negative emotions and thus have a negative impact on welfare, or not. Cortisol tended to be higher $(P=0.09)$, whether due to the expectation/loss of control or to the increased activity, or to both. In fish, the relationship between cortisol and affective states has not been established, but in humans it is well known that the hypothalamus-pituitary-adrenal axis is more sensitive to negative emotions than to positive ones [18].

\subsection{Effects of social isolation}

Social isolation, whether for 4 or 10 days, increases the cortisol levels of male tilapia in relation to the social group conditions. This fact suggests that isolation is a stressful procedure, which is in accordance with the fact that 0 . mossambicus is a group living species [52]. In this experiment males were placed in social isolation prior to the experimental treatment, which has been a routine procedure to minimise behavioural and androgen variation due to different social ranks $[33,53]$. However, data presented here show that this is not the most appropriate procedure to obtain baseline cortisol levels, since social isolation activated the hypothalamus-pituitary-interrenal axis. We suggest that the use of the cortisol levels from males kept in stable social groups (stock) as a proxy for a measure of cortisol baseline levels in this species. Even acknowledging that cortisol levels in control groups exposed to social isolation do not represent baseline values these were used as reference values in the analyses of cortisol levels of experimental treatments, since they are the matched groups in terms of experimental design. These analyses, suggest that predictable confinement and (predictable or unpredictable) presentation of food were both less stressful procedures than social isolation perse.

In conclusion, Mozambique tilapia males are able to appraise predictability of events. They show an increased cortisol response to unpredictable negative events. When there is a significant delay between signalling and actual occurrence of a predictable positive event, elements associated to the stress response can also occur. These findings demonstrate the occurrence of appraisal in fish with important welfare implications for the management of teleosts in captivity. Husbandry and experimental procedures should include the reliable signalling of aversive events and avoid delays of predictable attractive events, such as feeding times.

\section{Acknowledgments}

We thank Sandor Klis, Anja Visser and Charlotte Oostrom for their collaboration in the behavioural observations of experiment 1 , and 
Tânia Oliveira for the cortisol assays. We also thank Albert Ros and Humberto Rosa for their comments and suggestions to this manuscript. This study was funded by the Pluriannual Program of Fundação para a Ciência e a Tecnologia (FCT, UI\&D 331/2001) and L.G. was supported by a PhD fellowship from FCT (SFRH/BD/16162/2004).

\section{References}

[1] Cooper CL, Dewe P. Stress: A Brief History. Oxford, UK: Blackwell Publishing; 2004. p. 144.

[2] Lazarus RS. Stress and Emotion: A New Synthesis. New York, USA: Springer Publishing Company; 1999. p. 342.

[3] Ursin H, Eriksen HR. The cognitive activation theory of stress. Psychoneuroendocrinology 2004;29:567-92.

[4] Steckler T. The neuropsychology of stress. In: Steckler T, Kalin NH, Reul JMHM, editors. Handbook of Stress and the Brain. Part 1: The Neurobiology of Stress. Amsterdam, The Netherlands: Elsevier; 2005. p. 25-42.

[5] Désiré L, Boissy A, Veissier I. Emotions in farm animals: a new approach to animal welfare in applied ethology. Behav Processes 2002;60:165-80.

[6] Wendelaar-Bonga SE. The stress response in fish. Physiol Rev 1997;77:591-625.

[7] Iwama GK. The welfare of fish. Dis Aquat Organ 2007;75:155-8.

[8] Rose JD. The neurobehavioral nature of fishes and the question of awareness and pain. Rev Fish Sci 2002;10:1-38.

[9] Sneddon L. Assessing pain perception in fish from physiology to behaviour. Comp Biochem Physiol A Mol Integr Physiol 2007;146:S78.

[10] Yue S, Duncan IJH, Moccia RD. Investigating fear in rainbow trout (Oncorhynchus mykiss) using the conditioned-suppression paradigm. J Appl Anim Welf Sci 2008;11:14-27.

[11] Butler AB, Hodos W. Comparative Vertebrate Neuroanatomy: Evolution and Adaptation. New Jersey, USA: John Wiley \& Sons, Inc; 2005. p. 715.

[12] Chandroo KP, Duncan IJH, Moccia RD. Can fish suffer?: perspectives on sentience, pain, fear and stress. Appl Anim Behav Sci 2004;86:225-50.

[13] Rodriguez F, Broglio C, Duran E, Gomez A, Salas C. Neural mechanisms of learning in teleost fish. In: Brown C, Laland $\mathrm{K}$, Krause J, editors. Fish Cognition and Behaviour. Oxford, UK: Blackwell Publishing; 2006. p. 243-77.

[14] Stolte EH, de Mazon AF, Leon-Koosterziel KM, Jesiak M, Bury NR, Sturm A, et al. Corticosteroid receptors involved in stress regulation in common carp, Cyprinus carpio. J Endocrinol 2008;198:403-17.

[15] Barreto RE, Volpato GL, Pottinger TG. The effect of elevated blood cortisol levels on the extinction of a conditioned stress response in rainbow trout. Horm Behav 2006;50:484-8.

[16] Braithwaite VA. Cognitive ability in fish. In: Sloman KA, Wilson RW, Balshine S, editors. Behaviour and Physiology of Fish. Amesterdam, The Netherlands: Elsevier; 2006. p. 1-35.

[17] Galhardo L, Oliveira RF. Psychological stress and welfare in fish. ARBS Annu Rev Biomed Sci 2009;11:1-20.

[18] Lovallo WR. Stress \& Health: Biological and Psychological Interactions. Thousand Oaks, USA: Sage Publications; 2005.

[19] Sapolsky RM. Why Zebras Don't Get Ulcers. New York, USA: Henry Holt and Company; 2004.

[20] Weiss JM. Somatic effects of predictable and unpredictable shock. Psychosom Med 1970;32:397-408.

[21] Bassett L, Buchanan-Smith HM. Effects of predictability on the welfare of captive animals. Appl Anim Behav Sci 2007;102:223-45.

[22] Orsini C, Ventura R, Lucchese F, Puglisi-Allegra S, Cabib S. Predictable stress promotes place preference and low mesoaccumbens dopamine response. Physiol Behav 2002;75:135-41.

[23] Prior $\mathrm{H}$. Effects of predictable and unpredictable intermittent noise on spatial learning in rats. Behav Brain Res 2002;133:117-24.

[24] Whalen PJ. The uncertainty of it all. Trends Ecol Evol 2007;11:499-500.

[25] Bloomsmith MA, Lambeth SP. Effects of predictable versus unpredictable feeding schedules on chimpanzee behavior. Appl Anim Behav Sci 1995;44:65-74.

[26] Carlstead K. Predictability of feeding - its effect on agonistic behavior and growth in grower pigs. Appl Anim Behav Sci 1986;16:25-38.

[27] Gilbert-Norton LB, Leaver LA, Shivik JA. The effect of randomly altering the time and location of feeding on the behaviour of captive coyotes (Canis latrans). Appl Anim Behav Sci 2009;120:179-85.

[28] Wiepkema PR, Koolhaas JM. Stress and animal welfare. Anim Welf 1993;2: 195-218.
[29] Carlstead K. Effects of captivity on the behavior of wild mammals. In: Kleiman DG Allen ME, Thompson KV, Lumpkin S, editors. Wild Mammals in Captivity: Principles and Techniques. Chicago, USA: The University of Chicago Press; 1996. p. p317-33.

[30] Johannesson T, Ladewig J. The effect of irregular feeding times on the behaviour and growth of dairy calves. Appl Anim Behav Sci 2000;69:103-11.

[31] Waitt C, Buchanan-Smith HM. What time is feeding? How delays and anticipation of feeding schedules affect stump-tailed macaque behavior. Appl Anim Behav Sci 2001;75:75-85.

[32] Sánchez JA, López-Olmeda JF, Blanco-Vivesa B, Sánchez-Vázquez FJ. Effects of feeding schedule on locomotor activity rhythms and stress response in sea bream. Physiol Behav 2009;98:125-9.

[33] Oliveira RF, Carneiro LA, Canario AVM. No hormonal response in tied fights. Nature 2005;437:207-8.

[34] Winberg S, Lepage O. Elevation of brain 5-HT activity, POMC expression, and plasma cortisol in socially subordinate rainbow trout. Am J Physiol Regul Integr Comp Physiol 1998;274:R645-54

[35] Earley RL, Edwards JT, Aseem O, Felton K, Blumer LS, Karom M, et al. Social interactions tune aggression and stress responsiveness in a territorial cichlid fish (Archocentrus nigrofasciatus). Physiol Behav 2006;88:353-63.

[36] Gomez-Laplaza LM, Morgan E. The effect of time spent in isolation on the response to novel nonsocial stimulation in the angelfish Pterophyllum scalare. Can J Zool Rev Can Zool 2000;78:530-7.

[37] Gómez-Laplaza LM, Morgan E. Social isolation, agression, and dominance in attacks in juvenile angelfish, Pterophyllum scalare. Agress Behav 1993;19:213-22.

[38] Hannes R-P, Franck D. The effect of social isolation on androgen and corticosteroid levels in a cichlid fish (Haplochromis burtoni) and in swordtails (Xiphophorus helleri). Horm Behav 1983;17:292-301.

[39] Schjolden J, Backstrom T, Pulman KGT, Pottinger TG, Winberg S. Divergence in behavioural responses to stress in two strains of rainbow trout (Oncorhynchus mykiss) with contrasting stress responsiveness. Horm Behav 2005;48:537-44.

[40] Antunes RA, Oliveira RF. Hormonal anticipation of territorial challenges in cichlid fish. Proc Natl Acad Sci U S A Biol Sci 2009;106:15985-9.

[41] Martin P, Bateson P. Measuring Behaviour: An Introductory Guide. Cambridge: Cambridge University Press; 2007.

[42] Ross LG. Restraint, anaesthesia \& euthanasia. In: Wildgoose WH, editor. Veterinary Practice \& Procedures for Ornamental Fish. London, UK: British Small Animal Veterinary Association; 2001. p. 75-83.

[43] Foo JTW, Lam T]. Serum cortisol response to handling stress and the effect of cortisol implantation on testosterone level in the tilapia, Oreochromis mossambicus. Aquaculture 1993;115:145-58.

[44] Vilhunen S, Hirvonen H. Innate antipredator responses of Arctic charr (Salvelinus alpinus) depend on predator species and their diet. Behav Ecol Sociobiol 2003;55: $1-10$.

[45] Yue S, Moccia RD, Duncan IJH. Investigating fear in domestic rainbow trout Oncorhynchus mykiss, using an avoidance learning task. Appl Anim Behav Sci 2004:87:343-54.

[46] Spruijt BM, van den Bos R, Pijlman FTA. A concept of welfare based on reward evaluating mechanisms in the brain: anticipatory behaviour as an indicator for the state of reward systems. Appl Anim Behav Sci 2001;72:145-71.

[47] Manteuffel G, Langbein J, Puppe B. Increasing farm animal welfare by positively motivated instrumental behaviour. Appl Anim Behav Sci 2009;118:191-8.

[48] de Jonge FH, Tilly SL, Baars AM, Spruijt BM. On the rewarding nature of appetitive feeding behaviour in pigs (Sus scrofa): do domesticated pigs contrafreeload? Appl Anim Behav Sci 2008;114:359-72.

[49] de Jonge FH, Ooms M, Kuurman WW, Maes JHR, Spruijt BM. Are pigs sensitive to variability in food rewards? Appl Anim Behav Sci 2008;114:93-104.

[50] Dudink S, Simonse H, Marks I, de Jonge FH, Spruijt BM. Announcing the arrival of enrichment increases play behaviour and reduces weaning-stress-induced behaviours of piglets directly after weaning. Appl Anim Behav Sci 2006;101: 86-101.

[51] Ulyan MJ, Burrows AE, Buzzell CA, Raghanti MA, Marcinkiewicz JL, Phillips KA. The effects of predictable and unpredictable feeding schedules on the behavior and physiology of captive brown capuchins (Cebus apella). Appl Anim Behav Sci 2006;101:154-60.

[52] Oliveira RF, Almada VC. Dominance hierarchies and social structure in captive groups of the Mozambique tilapia Oreochromis mossambicus (Teleostei: Cichlidae). Ethol Ecol Evol 1996;8:39-55.

[53] Galhardo L, Correia J, Oliveira RF. The effect of substrate availability on behavioural and physiological indicators of welfare in the African cichlid (Oreochromis mossambicus). Anim Welf 2008;17:239-54. 